\title{
The p62/Keap1/Nrf2 axis in the control of C-2 induced human gastric cancer cell death switching between autophagy and apoptosis
}

\section{ZhenYa Wang}

Zhengzhou University

\section{Yong Guo}

Zhengzhou University

\section{En Zhang}

Zhengzhou University

QianHong Ban

Zhengzhou University

MengLin Wang

Zhengzhou University

XinXin Wu

Zhengzhou University

Lu Yu

Zhengzhou University

Lu Liu

Zhengzhou University

HaiYang Yu

Tianjin University of Traditional Chinese Medicine

Gi-Young Kim

Jeju National University

\section{YungHyun Choi}

Dongeui University: Dong Eui University

\section{YiChao Xu}

Zhengzhou University

HongDe Xu

Zhengzhou University

Cheng-Yun Jin ( $\nabla$ cyjin@zzu.edu.cn )

Zhengzhou University 
Keywords: C-2, p62, Keap1, Nrf2, Apoptosis, Autophagy

Posted Date: January 19th, 2021

DOI: https://doi.org/10.21203/rs.3.rs-147863/v1

License: (c) (i) This work is licensed under a Creative Commons Attribution 4.0 International License. Read Full License 


\section{Abstract \\ Background}

Compound $\mathrm{C}-2$ is a derivative of natural product Jaspine B and possesses anti-cancer activity against bladder cancer cells. However, little is known about its anti-cancer activity against gastric cancer. In this research, mechanism underlying anti-cancer effect of $\mathrm{C}-2$ in gastric cancer cells was well investigated.

\section{Methods}

Anti-cancer activities of C-2 were determined by MTT, western blotting and flow cytometry. A serial of specific inhibitors, immunoprecipitation, siRNA and immunofluorescence were utilized to explore signaling pathways affected by C-2.

\section{Results}

C-2 induces apoptosis in gastric cancer cells through the internal mitochondrial pathway, and triggers autophagy in gastric cancer cells through JNK/ERK pathway. Phosphorylated JNK/ERK further activates Beclin1 via disturbing Beclin-1/Bcl-xL or Beclin-1/Bcl-2 complexes, leading to autophagy and up-regulated p62. Next, p62 competitively binds keap1 to release Nrf2, thus promoting translocation of Nrf2 from cytoplasm to nucleus and triggering expression of Nrf2 target genes. Pharmacological inhibition or knockdown of key proteins in autophagy attenuates $\mathrm{C}-2$ induced cell apoptosis, indicating that autophagy antagonizes cell apoptosis induced by $\mathrm{C}-2$.

\section{Conclusion}

C-2 possesses anti-tumor activity against gastric cancer cells, while C-2 triggered-autophagy antagonizes cell arrest and apoptosis induced by $\mathrm{C}-2$ by upregulating Nrf2 in nucleus.

\section{Background}

Gastric cancer (GC) originating from the epithelium of gastric mucosa is one of the most common types of malignancy worldwide. Diagnosed at advanced stage because of lacking early signs or symptoms makes GC the third cause of cancer-associated mortality worldwide [1]. Surgery and chemotherapy remain the major treatment for gastric cancer. However, more than $50 \%$ patient will relapse and metastasis [2]. Therefore, gastric cancer is an urgent health problem to be resolved.

Natural product Jaspine $B$ is isolated from marine biological sponges and exhibits anti-tumor effect against human and mouse cancer cell lines $[3,4]$. Our group have reported that derivative of Jaspine B, C2 , could induce cell death in bladder cancer cells via apoptosis pathway [5]. Previous work showed that C- 
2 inhibited gastric cancer cells at micromolar level. Thus, mechanism and involved intracellular signal pathways underlying anti-gastric cancer cells of $\mathrm{C}-2$ are investigated in this study.

Apoptosis is a highly conservative programmed cell death, and resistance to apoptosis is one of the hallmarks of cancer [6]. Caspases are the most important proteins to execute apoptosis and can be divided into two categories: promoters and executioners. The former type consists of Caspase 2, 8, 9 and 10 , playing the role of initiating caspase cascade. The executioner caspases include Caspase 3,6 , and 7 [7]. According to the stimuli, apoptosis is cataloged into two pathways: extrinsic pathway and intrinsic pathway. The extrinsic pathway is triggered by death receptors on the cell surface, and mitochondria stress initiates internal pathway. Many anti-tumor agents exhibit anti-neoplastic activity through inducing apoptosis [8].

It has been reported that Jaspine B and its derivative C-2 could induce autophagy [5]. Autophagy is a double-edged sword to cancer according to the stage and microenvironment of tumor [8]. Autophagy plays an important role in regulating cell homeostasis, mediating the removal of dysfunctional or damaged organelles, which are digested for the needs of cell metabolism $[9,10]$. According to physiological function of autophagy and the process of "cargo" to be degraded, autophagy are divided into three different types: microautophagy, molecular chaperone-mediated autophagy and macroautophagy $[11,12]$. In this article, the term "autophagy" refers to macroautophagy. Autophagy is rigorously regulated in cells, and emerging evidences suggest that MAPK signaling pathway can induce autophagy [13]. Two key members of MAPK family, JNK (c-Jun N-terminal kinase) and ERK (extracellular signal-regulated kinase), can dissociate Bcl-2/Beclin-1 or Bcl-xL/Beclin-1 complexes to release Beclin-1, resulting in autophagy. $\mathrm{Bcl}-2$ and $\mathrm{Bcl}-\mathrm{xL}$ belong to anti-apoptotic $\mathrm{Bcl}-2$ protein family, levels of which will be decreased during apoptosis [14].

Sequestosome1 (SQSTM1, also known as p62) is a stress-inducible cellular protein, multiple domains of which make it a signaling hub [15]. On one hand, p62 can bind LC3 and serve as an adaptor for degradation of ubiquitinated substances during autophagy. On the other hand, p62 can bind Keap1 (the Kelch-like ECH associated protein 1) to release Nrf2 (Nuclear factor erythroid 2- related factor 2), which is an important transcriptional factor and induces expression of anti-oxidative proteins and enzymes.

In this study, we found that C-2 selectively showed cytotoxicity to gastric cancer cells and can induce mitochondria dependent apoptosis and autophagy. And C-2 triggered JNK/ERK activation led to autophagy via blocking interaction of Beclin-1/Bcl-xL or Beclin/Bcl-2 complexes. Autophagy at early stage antagonized C-2 induced cell arrest through activation of antioxidant molecule Nrf2. Our study is expected to provide some theoretical basis of cellular molecular biology and candidate compound C-2 for the development of new anti-gastric cancer agents.

\section{Materials And Methods}

\section{Reagents}


RPMI-1640 was purchased from Gibco (Grand island, NY, USA). Fetal bovine serum (FBS) was purchased from BI (Israel). 3-(4, 5-dimethyl-thiazol-2-yl)-2, 5-diphenyltetra-zolium bromide (MTT) was purchased from Sigma-Aldrich (St Louis, MO, USA), LY294002 was purchased from selleck (Texas, Houston, USA). SP600125 and SCH772984 were purchased from MCE (New Jersey, USA). Annexin-V/FITC Apoptosis Detection Kit was purchased from KeyGEN BioTech (Jiangsu, China). The lysis buffer, Nuclear and Cytoplasmic Protein Extraction Kit were purchased from Beyotime (Shanghai, China). The ECL Western blotting substrate kit was purchased from absin (Shanghai, China). Antibodies against LC3 (14600-1-AP), Beclin1 (66665-1-lg), $\beta$-actin (sc-1615) were purchased form Cell Signaling Technology (Danvers, MA, USA). Antibodies against Cleaved caspase-3 (ab2302), Cleaved caspase-9 (ab2324) were purchased from Abcam (Cambridge, MA, USA). Lipofectamine 2000 was purchased from ThermoFisher (Waltham, MA, USA). JC-1 fluorescent dye was purchased from Yeasen (Shanghai, China).

\section{Cell cultures and MTT assay}

293T, MGC803, HGC27, SGC7901 and GES1 (human gastric epithelial cells) were obtained from Chinese Academy of Science Cell Bank (Shanghai, China). Cells were treated with agents for indicated time, then add $5 \mathrm{mg} / \mathrm{ml} \mathrm{MTT}$ to the culture medium, and incubate cells at $37^{\circ} \mathrm{C}$ for $24 \mathrm{~h}$. Next remove the culture medium containing MTT and add $0.4 \mathrm{~mL}$ DMSO to solubilize the formazan crystals. Optical density for MTT assay was detected at $490 \mathrm{~nm}$ with microplate reader.

\section{Immunofluorescence and Immunoprecipitation analysis}

Cells were treated with agents for indicated time, then immunofluorescence and immunoprecipitation analysis were performed as reported previously [5].

\section{Western blot}

Gastric cancer cells were treated with agents for indicated time, total proteins were then collected and quantified by micro-BCA protein assay kit (P0012, Beyotime, Shanghai, China). Then the proteins were subjected to immunoblotting as previously described [16].

\section{Apoptosis analysis}

Cells were treated with indicated concentration of compounds for specific time, then cells were collected and stained with Annexin V and PI for 20 min. Next, cells were measured by flow cytometer. The data was quantified by FlowJo software.

\section{Measurement of mitochondria membrane potential $(M M P, \Delta \Psi)$}

Cells were treated with indicated concentration of compounds for specific time, then cells were collected and stained with JC-1 for 10 min. Next, cells were measured by flow cytometer. The data was quantified by FlowJo software. 
Cells seeded in 24-well plate were transfected with siRNA at a final concentration of $50 \mathrm{nM}$. siRNA (\#6394) against p62 were synthesized and purchased from Cell Signaling Technology (Danvers, MA, USA).

\section{Generation of knockdown cells lines}

The short hairpin RNA (shRNA) against Beclin1 was synthesized by TSINGKE (Shanghai, China) and incorporated into vector CD513B-U6. The shRNA sequence targeting Beclin1 was 5'-

GGACAACAAGTTTGACCATGC-3'. Lentivirus particles were generated by transfecting plasmids CD513BU6 and three auxiliary plasmids pGag-Pol, pRev and pVSV-G to 293T cells. Stable knockdown cell lines were transfected with lentivirus particles and selected with $4 \mu \mathrm{g} / \mathrm{mL}$ puromycin (P8833, Sigma-Aldrich, St Louis, USA).

\section{Statistical analysis}

All experiments were repeated at least three times, the data were presented as mean \pm SD. Differences between the experimental groups were determined by paired or unpaired Student's $t$ test. The smaller the $P$ value, the more significant the difference between the experimental groups, without significant difference $P>0.05$, significant difference * $P<0.05$, * $P<0.01$ and $* * P<0.001$.

\section{Results}

\section{C-2 significantly inhibits cell growth and induces apoptosis in gastric cancer cells.}

To test the anti-tumor efficacy of C-2, we examined the anti-proliferative activity of C-2 against three gastric cancer cells MGC803, HGC27 and SGC7901 and human gastric epithelial cell line GES-1. As shown in Fig. 1b, C-2 significantly inhibits cell viability of gastric cancer cell lines in dose-and timedependent manner compared with GES-1. It should be noted that the cell viability of human normal gastric epithelial cells GES-1 treated with $8 \mu \mathrm{M}$ of C-2 after $24 \mathrm{~h}$ was $95.01 \%$, indicating that C-2 showed minor toxic to GES1. Taken together, these results suggested that C-2 selectively exerted cytotoxicity against gastric cancer cells compared with normal gastric epithelial cell lines.

Given that cell density of MGC803 and HGC27 cells were gradually decreased after incubating with C-2 for $24 \mathrm{~h}$ (Fig. 2a), and apoptosis is one of the most common cell death processes, we performed flow cytometry analysis to examine whether apoptosis occurred. As shown in Fig. <link rid="fig2" >2</link $>$ b, C2 dose-dependently elevated the population of gastric cancer cells staining with PI and Annexin V-FITC, indicating that $\mathrm{C}-2$ significantly induced gastric cancer cells apoptosis. Proteins at the downstream of apoptosis pathway were further detected. Data showed that C-2 increased expression levels of CleavedCasepase3 and Cleaved-PARP in both MGC803 and HGC27 cells (Fig. 2c). We next used the mitochondria fluorescent probe $\mathrm{JC}-1$ to test the role of mitochondria in C-2-induced apoptosis. As shown in Fig. $2 \mathrm{~d}$, there was an obviously right shift of peak staining with $\mathrm{JC}-1$ monomers compared with the untreated cells, indicating the loss of mitochondria membrane potential. Western blot results showed that C-2 
gradually increased levels of pro-apoptosis proteins Bax and Cleaved-caspase 9 and decreased levels of anti-apoptosis proteins Bcl-2 and Bcl-xL in MGC803 cells (Fig. 2e). We wonder whether apoptosis play a vital role in the anti-tumor efficacy of $\mathrm{C}-2$, inhibitors of apoptosis were used to detect their effects on antiproliferative activity of C-2 against gastric cancer cells. As shown in Fig. $2 f$, cell viability of cells cotreated with C-2 and Z-VAD-FMK were similar with that treated with C-2 alone, indicating that C-2 induced cell arrest were resistant to apoptosis inhibition. Collectively, these results suggested that C-2 induced mitochondria-dependent apoptosis in gastric cancer cells, but inhibition of apoptosis can't rescue cell growth inhibited by $\mathrm{C}-2$.

\section{C-2 induced protective autophagy in gastric cancer cells.}

Based on the fact that preventing apoptosis could not reverse cell arrest induced by C-2 and previous works reported that Jaspine B and C-2 could induce autophagy [5], we attempt to investigate the function of autophagy in C-2 induced cell arrest. We first found the presence of autolysosome vacuoles in MGC803 cells treated with C-2, indicating the occurrence of autophagy (Fig. 3a). Proteins participating autophagy were further tested. As shown in Fig. 3b and Additional file 1: Fig. S1, expression levels of Beclin-1, LC3, ATG3 and ATG12 were markedly increased by C-2 in dose- and time-dependent way. To further verify C-2-induced autophagy, we examine the LC3 expression with immunofluorescence assay. Data showed that C-2 could trigger the accumulation of LC3 (Fig. 3c). Next, we use an inhibitor of autophagy, LY294002, to test the biology function of autophagy in anti-tumor activity of C-2. We found that LY294002 markedly enhanced the anti-proliferative activity of C-2 in both MGC803 and HGC27 cells, indicating that autophagy prevented C-2 induced cell arrest (Fig. 3d). The further western blot results showed that LY294002 could partially reverse the accumulation of LC3-II, and dramatically elevated the protein level of Cleaved-caspase 3 and Cleaved-PARP induced by C-2 (Fig. 3e). In summary, these results suggested that $\mathrm{C}-2$ could induce autophagy in gastric cancer cells and autophagy played the protective role against $\mathrm{C}-2$ induced cell arrest.

\section{C-2 induces autophagy by JNK/ERK pathway in gastric cancer cells}

Given that it is previously reported that the MAPK pathway could induce autophagy [17], key proteins of MAPK pathway are examined by western blot. As shown in Fig. 4a, C-2 significantly increased phosphorylation of JNK, ERK and c-Jun. We next utilized the JNK inhibitor SP600125 and ERK inhibitor $\mathrm{SCH} 772984$ to test the contribution of MAPK pathway to the anti-viability activity of C-2. As shown in Fig. 4b, combination of C-2 with SP600125 or SCH772984 further reduced cell viability compared with C2 alone in MGC803 cells, indicating that inhibition of JNK or ERK enhanced the anti-tumor activity of C-2. Data from apoptosis assay showed that combination of SP600125 and C-2 induced the apoptotic population of MGC803 cells with $44.5 \%$, which is higher than that of C-2 alone with $20.7 \%$. And combining SCH772984 and C-2 caused MGC803 cells apoptosis with $45.2 \%$, which is about 2 -fold of that of C-2 alone, suggesting that prevention of JNK or ERK enhanced C-2 induced apoptosis (Fig. 4c). Western blot analysis confirmed that SP600125 decreased phosphorylation of JNK and reduced C-2 induced LC3-II, while SCH772984 down-regulated phosphorylated ERK and LC3-II in MGC803 cells (Fig. 4d 
and e). Both SP600125 and SCH772984 further up-regulated the level of Cleaved-caspase 3, CleavedPARP and LC3-II induced by C-2, indicating that SP600125 and SCH772984 strengthened C-2 induced apoptosis via inhibition of autophagy. The similar results were observed in HGC27 cells (Additional file 1:

Fig. S2a and b). In summary, C-2 induced autophagy via JNK/ERK pathway, inhibition of which enhanced $\mathrm{C}-2$ induced cell arrest and apoptosis.

\section{C-2 triggered activation of JNK/ERK leads to autophagy through disturbing Beclin-1/Bcl-xL or Beclin- 1/Bcl-2 complexes}

Given that C-2 triggered autophagy attenuated C-2 induced arrest, we try to investigate the interaction between autophagy and apoptosis. Beclin-1 mediates crosstalk between autophagy and apoptosis, Beclin-1/Bcl-2 and Beclin-1/Bcl-xL complexes can resist Beclin-1 activity and prevent Beclin-1 dependent autophagy, phosphorylated of Bcl-2 or Bcl-xL can release free Beclin-1, which will induce autophagy [18, 19]. Therefore, we first performed co-immunoprecipitation assay to determine the interaction of Beclin1/Bcl-2 and Beclin-1/Bcl-xL. As shown in Fig. 5a, compound C-2 inhibited the binding of Bcl-2 and Bcl-xL proteins with Beclin-1. Studies have reported that JNK and ERK can promote the phosphorylation of Bcl2/Bcl-xL and lead to the dissociation of Beclin-1 form Bcl-2/Bcl-xL, leaving Beclin-1 in an activated state and triggering autophagy [7]. To determine whether JNK/ERK participates in C-2 induced autophagy via Beclin-1, JNK inhibitor SP600125 and ERK inhibitor SCH772984 were used. As shown in Fig. 5b and c, SP600125 or SCH772984 markedly reversed the dissociation of Bcl-2/Beclin-1 and Bcl-xL/Beclin-1 complexes induced by $\mathrm{C}-2$, indicating that phosphorylated JNK triggered by $\mathrm{C}-2$ can further activate Beclin-1. We next downregulated Beclin-1 with shRNA to test whether Beclin-1 affected anti-tumor efficacy of C-2. As shown in Fig. 5d, the cell survival rates of normal and Beclin-1 knockdown MGC803 cells affected by C-2 at $2 \mu \mathrm{M}$ were $95.40 \%$ and $53.27 \%$, respectively, suggesting that Beclin- 1 antagonized C-2 induced cell arrest. The Western blot results further showed that accumulation of LC3-II was markedly decreased and apoptosis-related proteins Cleaved-Caspase 3 and Cleaved-PARP were significantly upregulated in Beclin-1 knockdown MGC803 cells compared with that in normal MGC803 cells, suggesting that knockdown of Beclin-1 enhanced C-2 induced apoptosis via inhibiting autophagy (Fig. 5e). Taken together, C-2 phosphorylated and activated JNK and ERK protein, which further activated Beclin-1 via disturbing Beclin-1/Bcl-xL or Beclin-1/Bcl-2 complexes, thus attenuating C-2 induced cell arrest.

\section{p62/Keap1/Nrf2 pathway controls C-2 induced cell arrest by switching from autophagy to apoptosis}

Since p62 protein plays an important role in the process of autophagy [20], we try to investigate the effect of p62 on C-2 induced cell arrest. As shown in Fig. 6a, cell viability was markedly decreased by C-2 in MGC803 cells with p62 knockdown compared with that of normal MGC803 cells, suggesting that p62 attenuated $\mathrm{C}-2$ induced cell arrest. We next performed western blot to examine protein alterations and found that expressing level of p62 and HO-1 were increased in a time-dependent manner, proteins Nrf2 and NQ01 were upregulated at first $6 \mathrm{~h}$ and then gradually decreased, while Keap1 has no observed change (Fig. 6b). It is reported that p62 competitively bind Keap1 to release Nrf2, resulting in nuclear 
translocation of Nrf2, thus we test the interaction of p62 and Keap1 by immunoprecipitation assay [21]. As shown in Fig. 6c, binding of p62 with Keap1 gradually increased at first $6 \mathrm{~h}$ treatment and then decreased. In accordance with that, accumulation of Nrf2 in nuclear elevated in a time-dependent way and reached the peak at first $6 \mathrm{~h}$ treatment, and decreased after $6 \mathrm{~h}$ treatment (Fig. $6 \mathrm{~d}$ ). Results from Immunofluorescence assay showed that Nrf2 accumulated in nuclear after C-2 treatment for $6 \mathrm{~h}$, further proved upregulation of Nrf2 induced by C-2 (Fig. 6e). Preventing autophagy by LY294002, SP600125 and SCH772984, or knockdown of Beclin-1 also decreased expression of p62 and HO-1, suggesting that C-2 upregulated p62 via JNK/ERK/Beclin-1 pathway (Fig. 7a-C). In addition, SP600125 and SCH772984 can reverse elevated interaction between p62 and Keap1 induced by C-2 (Fig. 7d-e).

Given that Nrf2 and its target NQ01 reach the peak after C-2 treatment for $6 \mathrm{~h}$, we designed different compound treatment strategy to test effects of autophagy inhibitor on C-2 induced cell arrest. As shown in Fig. $6 \mathrm{f}$, inhibition of autophagy by BafA1 with $24 \mathrm{~h}$ or first $6 \mathrm{~h}$ strengthened C-2 induced cell arrest, while combination of $\mathrm{C}-2$ and BafA1 at later $18 \mathrm{~h}$ have no effects on $\mathrm{C}-2$ induced cell arrest, suggesting that C-2 triggered autophagy antagonized C-2 induced cell arrest via upregulation of Nrf2 and NQ01. Because antioxidant system Nrf2/NQO1 is always triggered by oxidative stress, we examined the effect of ROS scavenger N-acetyl cysteine (NAC) on C-2 induced cell arrest. Unexpectedly, data showed that NAC have no effect on anti-proliferative activity of C-2 (Additional file 1: Fig. S3). In summary, C-2 triggeredautophagy antagonized C-2 induced cell arrest via p62/Nrf2 signaling pathway.

\section{Discussion}

It has long been reported that Jaspine B and its derivative $\mathrm{C}-2$ have potent cytotoxicity against tumor cell lines $[4,5,22]$. But anti-tumor effect and underlying mechanism of C-2 in gastric cancer are still unknown. In this study, we have confirmed that C-2 can induce apoptosis via mitochondria pathway in gastric cancer cells. At the same time, C-2 triggered elevation of phosphorylated JNK/ERK kinases, which can further disrupt complexes of Beclin-1/Bcl-xL or Beclin-1/Bcl-2, resulting in occurrence of autophagy. In the following autophagy process, increased binding of p62 with keap1 caused more Nrf2 in nucleus and upregulation of Nrf2 target genes NQO1 and HO1 [23], which attenuated C-2 induced cell arrest and apoptosis (Fig. 7f).

We found that C-2 induced mitochondria dependent apoptosis in gastric cancer cells, while apoptosis inhibitors had no effect on C-2 induced cell arrest. Cell necrosis inhibitor Nec-1 and ROS eliminator NAC were used to exclude the participation of necrosis and ROS stress in C-2 induced cell arrest (Additional file 1: Fig. S4). Serial inhibitors of autophagy markedly augmented anti-proliferative activity of C-2, which was in accordance with previous work [5]. Further studies need to be conducted to explore how C-2 induces cell apoptosis.

It is well known that autophagy play double edge effect in tumor survival and development [24]. Autophagy promotes tumor growth through removing and recycling abnormal or dysfunctional cell components [4]. While autophagy could also inhibit tumor growth through inducing cell death [25]. We 
observed that autophagy inhibitor LY29004 enhanced C-2 induced cell arrest, indicating that autophagy played protective role in C-2 induced cell arrest. Numerous evidences suggest that MAPKs involve in cell death and autophagy $[13,26,27]$. Increasing phosphorylation of JNK/ERK/p38 mediated by C-2 was found in our study. Further data showed that JNK/ERK led to autophagy through elevating free from of Beclin-1, which was consistent with previous reports [27, 28]. Results that knockdown of Beclin-1 prevented C-2 induced autophagy and elevated C-2 induced cell arrest further proved the involvement of Beclin-1 in C-2 induced autophagy. Therefore, C-2 triggered autophagy through JNK/ERK/Beclin-1 cascade pathway and prevention of which increased C-2 induced cell arrest.

It is found that JNK/ERK had a complicated relationship with p62-Nrf2 pathway [29-31]. Inhibition of autophagy through preventing JNK and ERK signaling pathways increases the mortality of cancer cells and achieves better therapeutic effect via Nrf2 pathway [32,33]. We observed that p62 was gradually elevated by $\mathrm{C}-2$ in gastric cancer cells for as long as $24 \mathrm{~h}$, while Nrf2 and its target gene encoding protein NQ01 increased at first $6 \mathrm{~h}$ and then progressively decreased. It is reported that $\mathrm{p} 62$ competitively binds Keap1 with Nrf2, resulting in translocation of Nrf2 from cytoplasm into nucleus, thereby activating the Nrf2 signaling pathway [21,34]. Our results showed that C-2 elevated the binding of p62 with Keap1 and Nrf2 accumulation in nucleus in a time-dependent manner at first $6 \mathrm{~h}$ treatment, which was in accordance with the upon data. It has been reported that inhibition of Nrf2 signaling pathway can activate apoptosis [33]. Autophagy inhibitor BafA1 prevented the binding of p62 and Keap1 induced by C-2 at the endpoint of $6 \mathrm{~h}$, and co-treatment of BafA1 with C-2 for first 6 hours or total $24 \mathrm{~h}$ enhanced C-2 induced cell arrest, while co-incubation of BafA1 with $\mathrm{C}-2$ for later $18 \mathrm{~h}$ have no effect on cell viability inhibited by $\mathrm{C}-2$. These results suggested that C-2 triggered autophagy antagonized C-2 induced cell arrest through activation of Nrf2 pathway. Results that JNK/ERK inhibitors and knockdown of Beclin-1 prevented interaction of p62 and Keap 1 and accumulation of p62 triggered by C-2 further proved that autophagy triggered Nrf2 pathway resisted cell arrest and apoptosis induced by $\mathrm{C}-2$.

\section{Conclusions}

In this study, we found that Jaspine B derivative, C-2, selectively showed cytotoxicity to gastric cancer cells and can induce mitochondria dependent apoptosis. C-2 triggered JNK/ERK activation led to autophagy via blocking interaction of Beclin-1/Bcl-xL or Beclin/Bcl-2 complexes. Autophagy at early stage antagonized C-2 induced cell arrest through activation of antioxidant molecule Nrf2.

\section{Abbreviations}

p62

SQSTM1 (sequestosome 1)/p62;

JNK

C-Jun N-terminal kinase;

ERK

extracellular signal-regulated kinase; 
Keap1

The Kelch-like ECH associated protein 1;

Nrf2

Nuclear factor erythroid 2- related factor 2;

MMP

Mitochondrial membrane potential;

LC3-II

Microtubule-associated protein 1A/1B-light chain 3II

NAC

$\mathrm{N}$-Acetyl-L-cysteine;

$\mathrm{Nec}-1$

Necrostatin-1.

\section{Declarations}

\section{Ethics approval and consent to participate}

Not applicable

\section{Consent for publication}

Not applicable

\section{Availability of data and materials}

All data and materials can be provided upon reasonable request.

\section{Competing interests}

The authors declare that they have no competing interests.

\section{Funding}

This study was supported by the National Natural Science Foundation of China (81973529 for ChengYun Jin), the Science and Technology Program of Henan Province (202102310152 for Yi Chao Xu).

\section{Authors' contributions}

ZYW, YG, and EZ performed majority experiments, analyzed data and wrote original draft. QHB, MLW and XXW knocked down the p62 and Beclin1. LL and HYY performed Immunofluorescence assay. GYK and YHC analyzed data. YCX, HDX and YCJ conceived, designed the experiments and revised the draft of manuscript. All authors read and approved the final manuscript.

\section{Acknowledgements}




\section{References}

1. Lim SC, Jeon HJ, Kee KH, Lee MJ, Hong R, Han SI. Andrographolide induces apoptotic and nonapoptotic death and enhances tumor necrosis factor-related apoptosis-inducing ligand-mediated apoptosis in gastric cancer cells. Oncology Letters. 2017;13(5):3837-44.

2. Chang CT, Hseu YC, Thiyagarajan V, Lin KY, Way TD, Korivi M, et al. Chalcone flavokawain B induces autophagic-cell death via reactive oxygen species-mediated signaling pathways in human gastric carcinoma and suppresses tumor growth in nude mice. Archives of Toxicology. 2017;91(10):3341-64.

3. Garcia V, Le Faouder P, Dupuy A, Levade T, Ballereau S, Genisson Y. A Novel Jaspine BCeramide Hybrid Modulates Sphingolipid Metabolism. Chemistry \& Biodiversity. 2015;12(7):1115-25.

4. Zhang E, Wang S, Li LL, Hua YG, Yue JF, Li JF, et al. Discovery of novel jaspine B analogues as autophagy inducer. Bioorganic \& Medicinal Chemistry Letters. 2018;28(3):497-502.

5. Yu HY, Wu CL, Wang XY, Ban QH, Quan CH, Liu MB, et al. SP600125 enhances C-2-induced cell death by the switch from autophagy to apoptosis in bladder cancer cells. Journal of Experimental \& Clinical Cancer Research. 2019;38(1).

6. Vandewalle V, Essaghir A, Bollaert E, Lenglez S, Graux C, Schoemans H, et al. miR-15a-5p and miR-21$5 p$ contribute to chemoresistance in cytogenetically normal acute myeloid leukaemia by targeting PDCD4, ARL2 and BTG2. Journal of Cellular and Molecular Medicine. 2020.

7. Su ZY, Yang ZZ, Xu YQ, Chen YB, Yu Q. MicroRNAs in apoptosis, autophagy and necroptosis. Oncotarget. 2015;6(11):8474-90.

8. Kimura T, Takabatake Y, Takahashi A, Isaka Y. Chloroquine in Cancer Therapy: A Double-Edged Sword of Autophagy. Cancer Research. 2013;73(1):3-7.

9. Mizushima N, Levine B, Cuervo AM, Klionsky DJ. Autophagy fights disease through cellular selfdigestion. Nature. 2008;451(7182):1069-75.

10. Bagam P, Kaur G, Singh DP, Batra S. In vitro study of the role of FOXO transcription factors in regulating cigarette smoke extract-induced autophagy. Cell Biology and Toxicology. 2020.

11. Mesquita A, Glenn J, Jenny A. Differential activation of eMl by distinct forms of cellular stress. Autophagy. 2020.

12. Andrade-Tomaz M, de Souza I, Rocha CRR, Gomes LR. The Role of Chaperone-Mediated Autophagy in Cell Cycle Control and Its Implications in Cancer. Cells. 2020;9(9).

13. He W, Wang Q, Srinivasan B, Xu J, Padilla MT, Li Z, et al. A JNK-mediated autophagy pathway that triggers C-IAP degradation and necroptosis for anticancer chemotherapy. Oncogene. 2014;33(23):3004-13.

14. Kapoor I, Bodo J, Hill BT, Hsi ED, Almasan A. Targeting BCL-2 in B-cell malignancies and overcoming therapeutic resistance. Cell Death \& Disease. 2020;11(11). 
15. Katsuragi Y, Ichimura Y, Komatsu M. p62/SQSTM1 functions as a signaling hub and an autophagy adaptor. Febs Journal. 2015;282(24):4672-8.

16. Zhang SY, Li TY, Zhang L, Wang XY, Dong HQ, Li LL, et al. A novel chalcone derivative S17 induces apoptosis through ROS dependent DR5 up-regulation in gastric cancer cells. Scientific Reports. $2017 ; 7$.

17. Zhou YY, Li Y, Jiang WQ, Zhou LF. MAPK/JNK signalling: a potential autophagy regulation pathway. Bioscience Reports. 2015;35.

18. Kim SY, Song XX, Zhang L, Bartlett DL, Lee YJ. Role of Bcl-xL/Beclin-1 in interplay between apoptosis and autophagy in oxaliplatin and bortezomib-induced cell death. Biochemical Pharmacology. 2014;88(2):178-88.

19. Jeong SJ, Zhang XY, Rodriguez-Velez A, Evans TD, Razani B. p62/SQSTM1 and Selective Autophagy in Cardiometabolic Diseases. Antioxidants \& Redox Signaling. 2019;31(6):458-71.

20. Moscat J, Diaz-Meco MT, Wooten MW. Signal integration and diversification through the p62 scaffold protein. Trends in Biochemical Sciences. 2007;32(2):95-100.

21. Ichimura $Y$, Waguri S, Sou $Y$, Kageyama S, Hasegawa J, Ishimura R, et al. Phosphorylation of p62 Activates the Keap1-Nrf2 Pathway during Selective Autophagy. Molecular Cell. 2013;51(5):618-31.

22. Kuroda I, Musman M, Ohtani II, Ichiba T, Tanaka J, Gravalos DG, et al. Pachastrissamine, a cytotoxic anhydrophytosphingosine from a marine sponge, Pachastrissa sp. Journal of Natural Products. 2002;65(10):1505-6.

23. Jin CY, Molagoda IMN, Karunarathne WAHM, Kang SH, Park C, Kim GY, et al. TRAIL attenuates sulforaphane-mediated Nrf2 and sustains ROS generation, leading to apoptosis of TRAIL-resistant human bladder cancer cells. Toxicology and Applied Pharmacology. 2018;352:132-41.

24. Li CJ, Liao WT, Wu MY, Chu PY. New Insights into the Role of Autophagy in Tumor Immune Microenvironment. International Journal of Molecular Sciences. 2017;18(7).

25. Leng ZG, Lin SJ, Wu ZR, Guo YH, Cai L, Shang HB, et al. Activation of DRD5 (dopamine receptor D5) inhibits tumor growth by autophagic cell death. Autophagy. 2017;13(8):1404-19.

26. Liu T, Wu L, Wang D, Wang $\mathrm{H}$, Chen J, Yang C, et al. Role of reactive oxygen species-mediated MAPK and NF-kappaB activation in polygonatum cyrtonema lectin-induced apoptosis and autophagy in human lung adenocarcinoma A549 cells. J Biochem. 2016;160(6):315-24.

27. Wang $C$, Yu Z, Shi X, Tang X, Wang Y, Wang X, et al. Triclosan Enhances the Clearing of Pathogenic Intracellular Salmonella or Candida albicans but Disturbs the Intestinal Microbiota through mTORIndependent Autophagy. Front Cell Infect Microbiol. 2018;8:49.

28. Goodall ML, Fitzwalter BE, Zahedi S, Wu M, Rodriguez D, Mulcahy-Levy JM, et al. The Autophagy Machinery Controls Cell Death Switching between Apoptosis and Necroptosis. Developmental Cell. 2016;37(4):337-49.

29. Zou X, Feng ZH, Li Y, Wang Y, Wertz K, Weber P, et al. Stimulation of GSH synthesis to prevent oxidative stress-induced apoptosis by hydroxytyrosol in human retinal pigment epithelial cells: 
activation of Nrf2 and JNK-p62/SQSTM1 pathways. Journal of Nutritional Biochemistry. 2012;23(8):994-1006.

30. Bucolo C, Drago F, Maisto R, Romano GL, D'Agata V, Maugeri G, et al. Curcumin prevents high glucose damage in retinal pigment epithelial cells through ERK1/2-mediated activation of the Nrf2/HO-1 pathway. Journal of Cellular Physiology. 2019;234(10):17295-304.

31. Yin HB, Yang XY, Gu W, Liu Y, Li XY, Huang XL, et al. HMGB1-mediated autophagy attenuates gemcitabine-induced apoptosis in bladder cancer cells involving JNK and ERK activation. Oncotarget. 2017;8(42):71642-56.

32. Li T, Xu XH, Tang ZH, Wang YF, Leung CH, Ma DL, et al. Platycodin D induces apoptosis and triggers ERK- and JNK-mediated autophagy in human hepatocellular carcinoma BEL-7402 cells. Acta Pharmacologica Sinica. 2015;36(12):1503-13.

33. Yu HY, Zhang J, Ji Q, Yu KY, Wang PY, Song M, et al. Melatonin alleviates aluminium chloride-induced immunotoxicity by inhibiting oxidative stress and apoptosis associated with the activation of Nrf2 signaling pathway. Ecotoxicology and Environmental Safety. 2019;173:131-41.

34. Zhang W, Feng C, Jiang H. Novel target for treating Alzheimer's Diseases: Crosstalk between the Nrf2 pathway and autophagy. Ageing research reviews. 2020;65:101207.

\section{Figures}

A

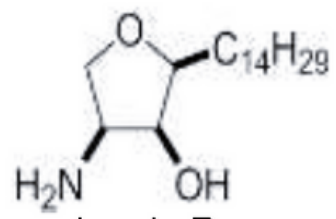

Jaspin B

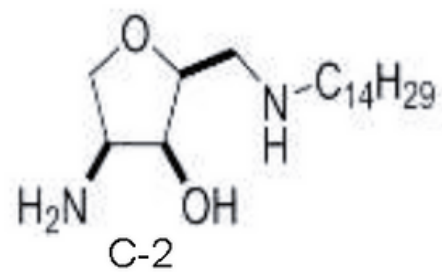

B

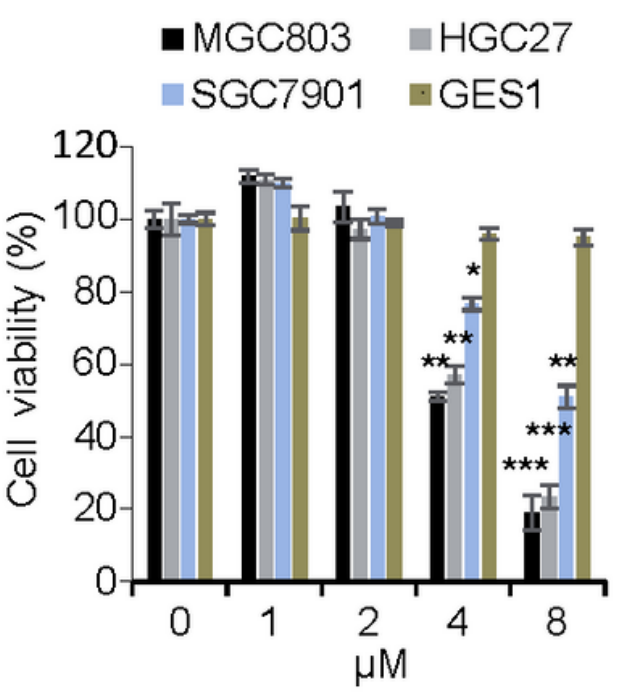

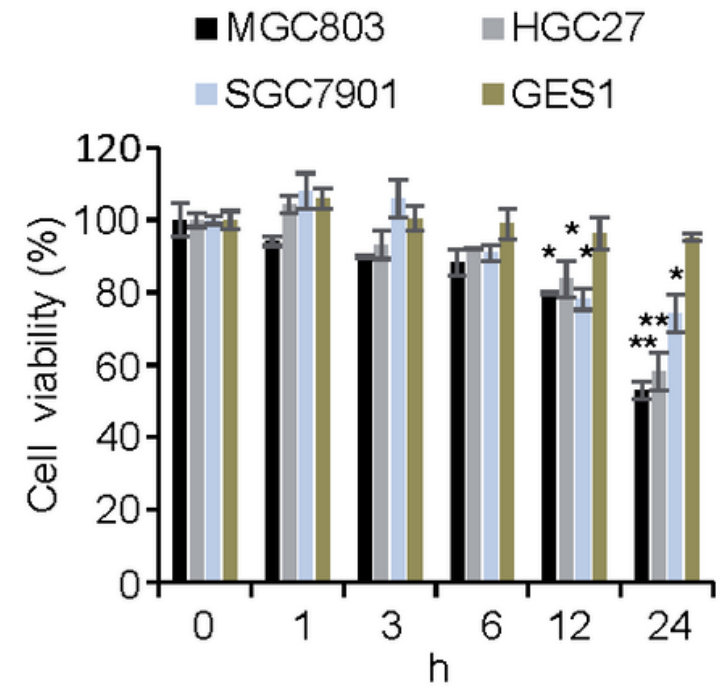

Figure 1

Compound C-2 selectively inhibits cell growth in gastric cancer cells. a Chemistry structural formulas of Jaspine B and C-2. b Selected cell lines were treated with compound C-2 for $24 \mathrm{~h}$ (left) or at $4 \mu \mathrm{M}$ for indicated time (right), cell viabilities were then tested by MTT assay. 
A

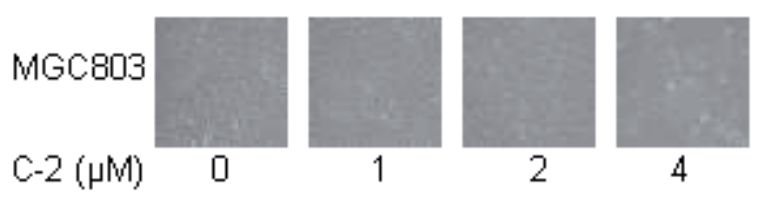

$\mathrm{C}-2(\mu \mathrm{M})$

1
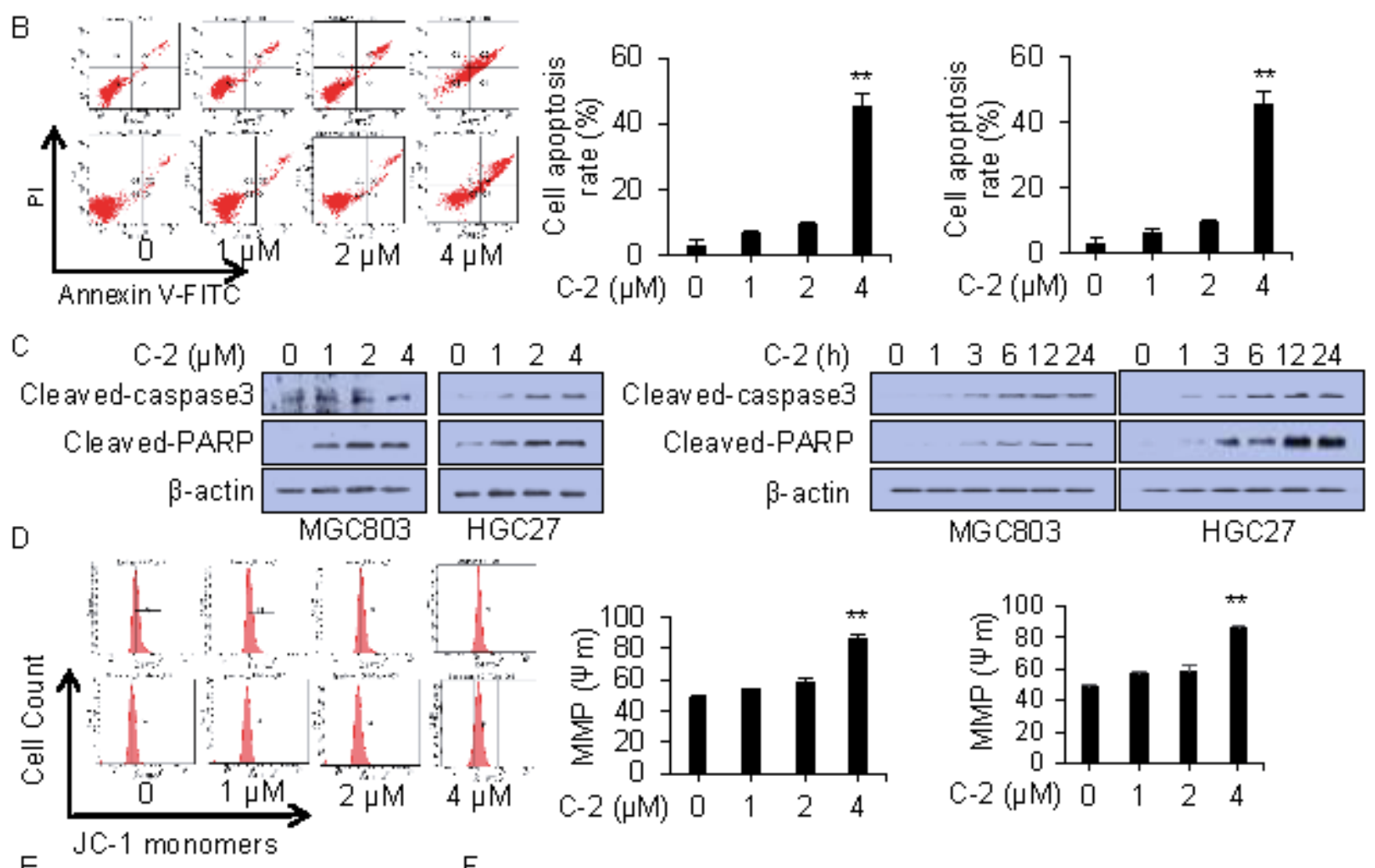

E

$C-2(\mu M) \quad 0 \quad 1 \quad 2 \quad 4$

Bax

Bcl-2

$\mathrm{Bcl}-\mathrm{xL}$
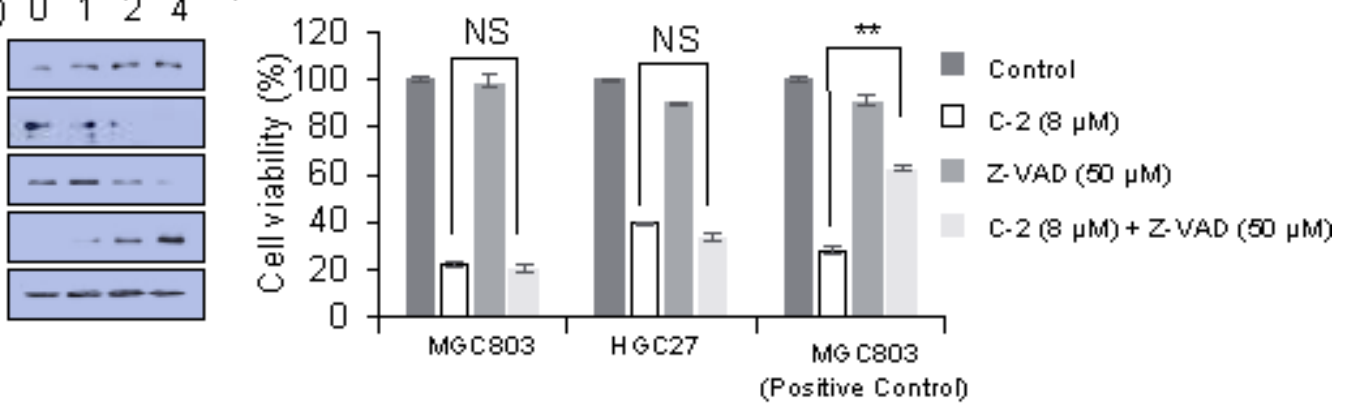

Figure 2

Compound C-2 induces mitochondria dependent apoptosis in gastric cancer cells. a Cells treated with C-2 for $24 \mathrm{~h}$ were observed under the inverted microscope. b Annexin V/PI staining apoptosis assay was performed to MGC803 cells treated with C-2 for $24 \mathrm{~h}$. c MGC803 and HGC27 cells were treated with C2 for $24 \mathrm{~h}$ or for indicated time at $4 \mu \mathrm{M}$, indicated proteins were detected by western blot. d Cells were treated with C-2 at indicated concentrations for $24 \mathrm{~h}$, the mitochondria membrane potential $(\Delta \Psi)$ of cells was then detected. e Indicated proteins in MGC803 cells treated with C-2 for $24 \mathrm{~h}$ were determined by western blot. $\mathrm{f}$ Cells were treated with indicated compounds for $24 \mathrm{~h}$, cell viability was measured by MTT assay. 
A

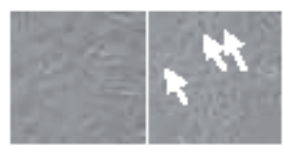

$\mathrm{C}-2(\mu \mathrm{M}) \quad 0 \quad 2$

$\mathrm{B}$

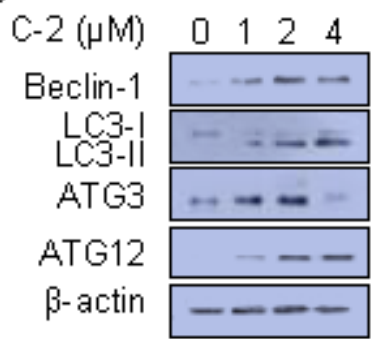

E

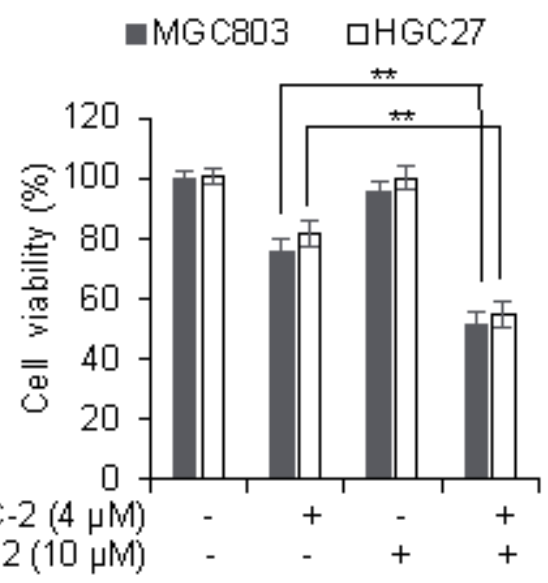

C

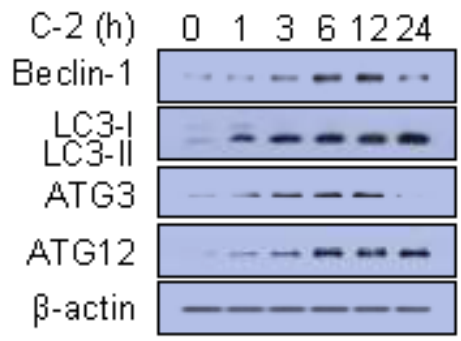

D

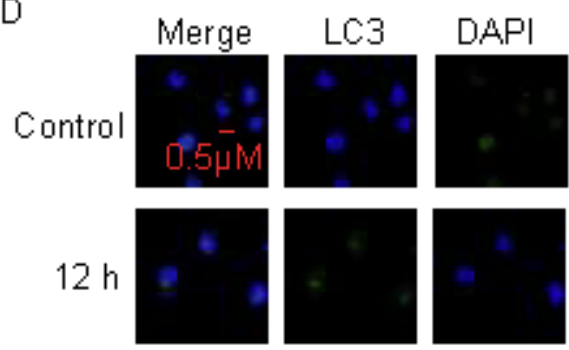

$24 \mathrm{~h}$
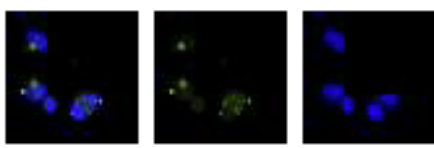

$\mathrm{F}$

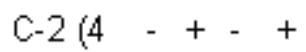

LY294002 (10HW) - + + +

Cleaved-caspase 3

Cleaved-PARP

LC3-I

LC3-II

$\beta$-actin

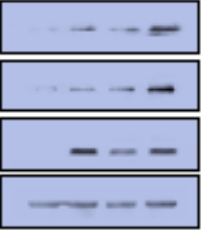

\section{Figure 3}

Compound C-2 induces protective autophagy in gastric cancer cells. a MGC803 cells were treated with $2 \mu \mathrm{M}$ of $\mathrm{C}-2$ for $24 \mathrm{~h}$, cells were then observed under the inverted microscope. MGC803 cells were treated with $\mathrm{C}-2$ for $24 \mathrm{~h}$ at indicated doses (b) or for different time at $4 \mu \mathrm{M}(\mathrm{c})$, indicated proteins were detected by western blot. $d$ Immunofluorescence assay was performed to MGC803 cells treated with C-2 (4 $\mu \mathrm{M})$ for indicated time. e cells were treated with indicated compounds for $12 \mathrm{~h}$, cell viabilities were then tested by MTT assay. $\mathrm{f} \mathrm{MGC803}$ cells were treated with compounds for $12 \mathrm{~h}$, indicated proteins were then detected by western blot. 


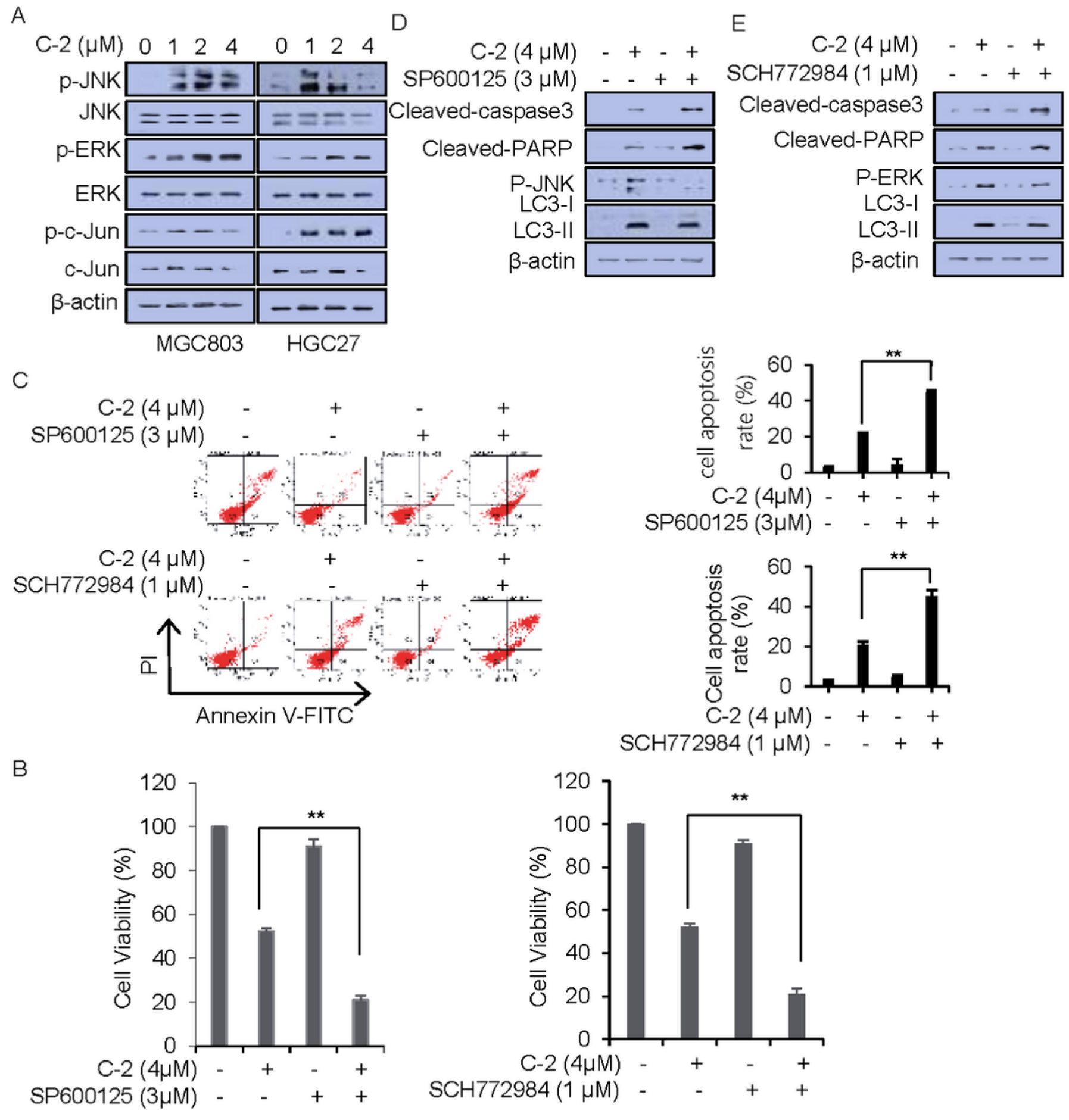

\section{Figure 4}

Inhibition of JNK/ERK increases C-2 induced apoptosis via reducing autophagy. a MGC803 and HGC27 cells were treated with $\mathrm{C}-2$ for $24 \mathrm{~h}$ at indicated doses, indicated proteins were detected by western blot. MGC803 cells were treated with indicated agents for $24 \mathrm{~h}$, cell viability (b) and cell apoptosis (c) were then measured. MGC803 cells were pretreated with with SP600125 (d) or SCH772984 (e) respectively for $1 \mathrm{~h}$, then C-2 was added to co-incubation for $12 \mathrm{~h}$, indicated proteins were detected by western blot. 


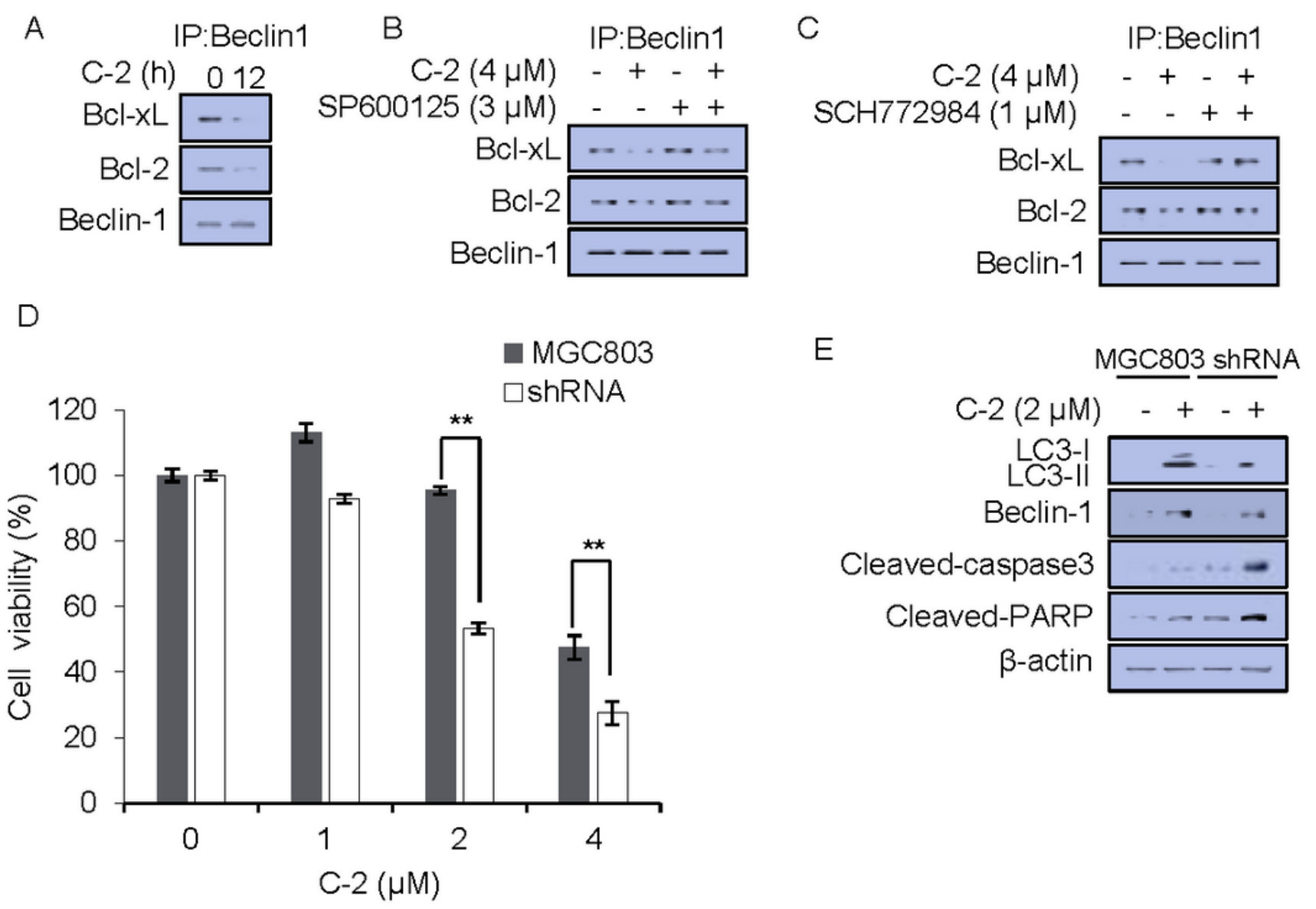

Figure 5

Upregulated p62 attenuates C-2 induced cell arrest via accumulation of Nrf2 in nucleus. a MGC803 cells were downregulated p62 with siRNA alone or co-treated with C-2 for $12 \mathrm{~h}$, cell viability was detected by MTT assay. b MGC803 cells were treated with $4 \mu \mathrm{M} \mathrm{C}-2$ for indicated time, specific proteins were determined by western blot. c MGC803 cells were treated with $4 \mu \mathrm{M} \mathrm{C}-2$ for indicated time. IP assay was performed to detect indicated proteins. d MGC803 cells were treated with $4 \mu \mathrm{M} \mathrm{C}-2$ for indicated time, Nrf2 was measured in cytoplasm and nucleus respectively by western blot. e MGC803 cells were treated with $4 \mu \mathrm{M} \mathrm{C}-2$ for $6 \mathrm{~h}$, Nrf2 was determined by Immunofluorescence assay. f MGC803 cells were treated with agents for indicated time, cell viability was measured by MTT assay. $\mathrm{g}$ MGC803 cells were treated with agents for $6 \mathrm{~h}$, IP assay was performed to detect indicated proteins. 


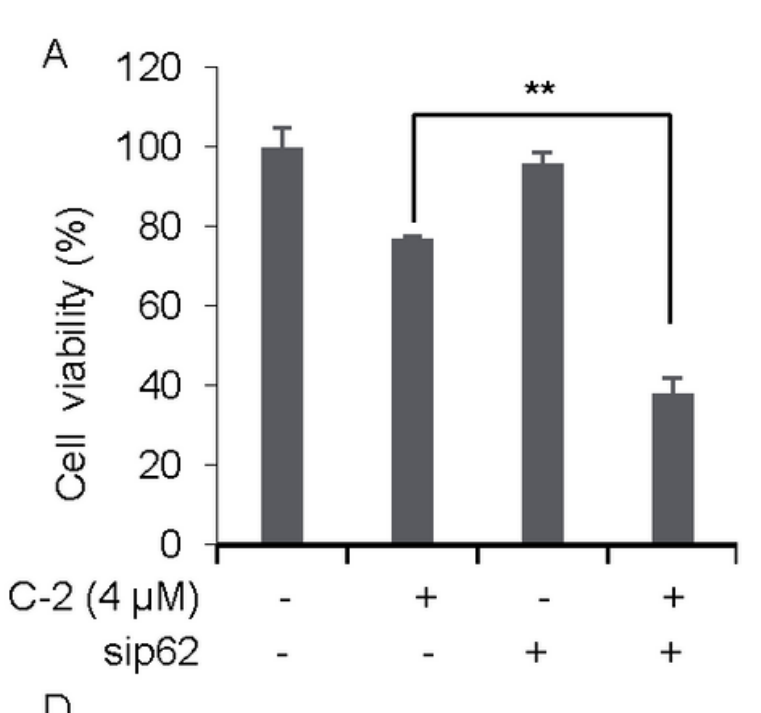

B
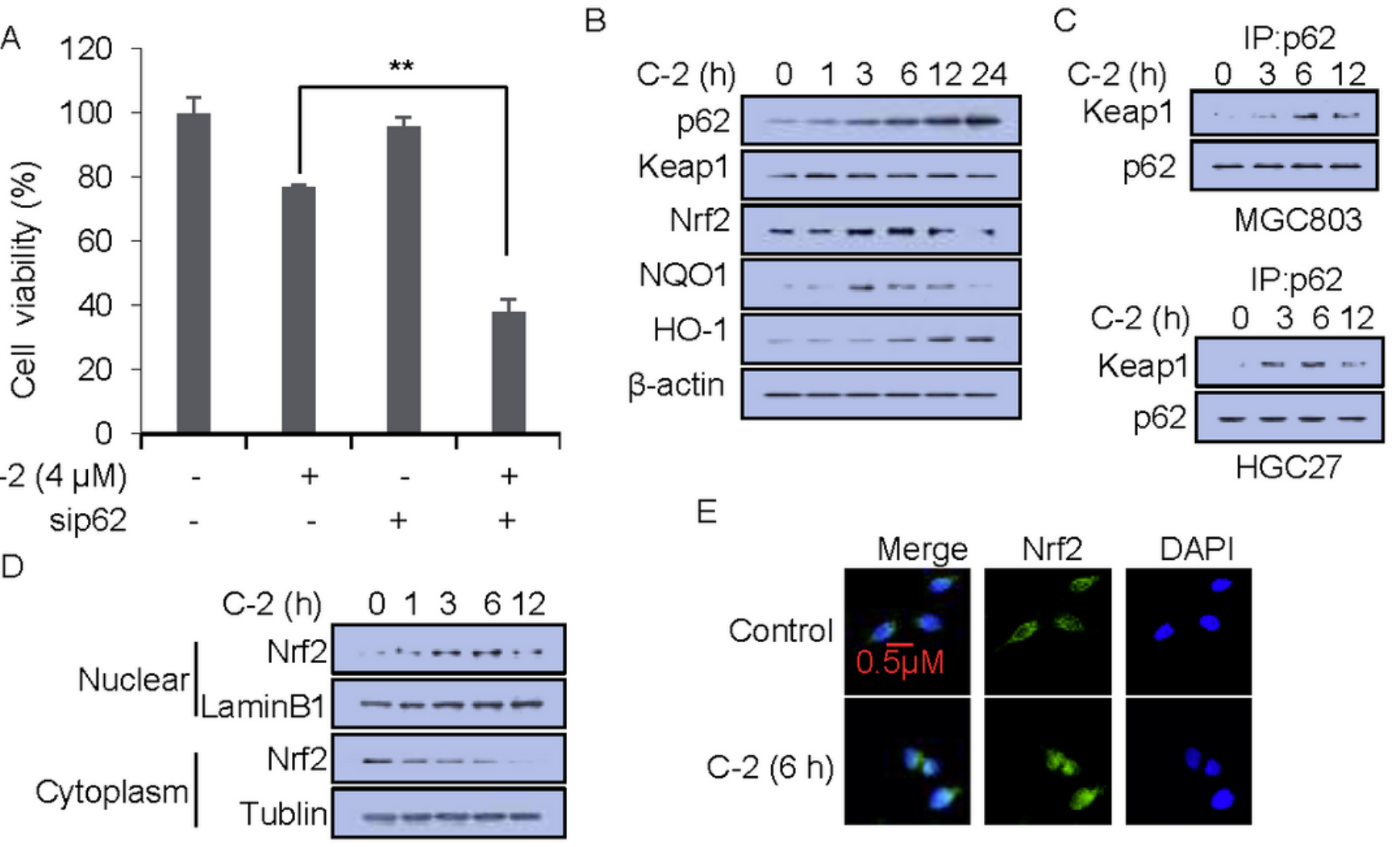

E

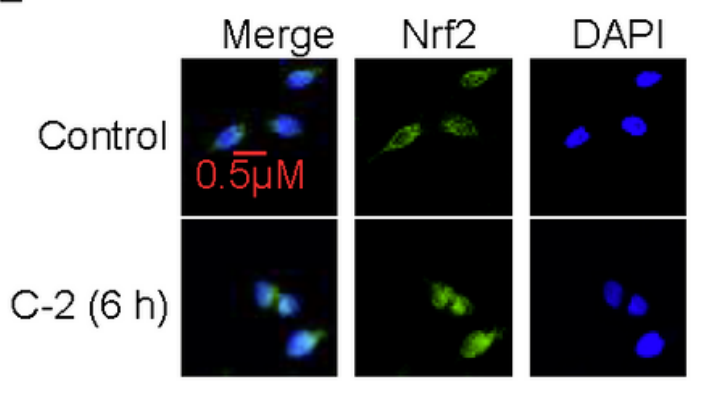

F

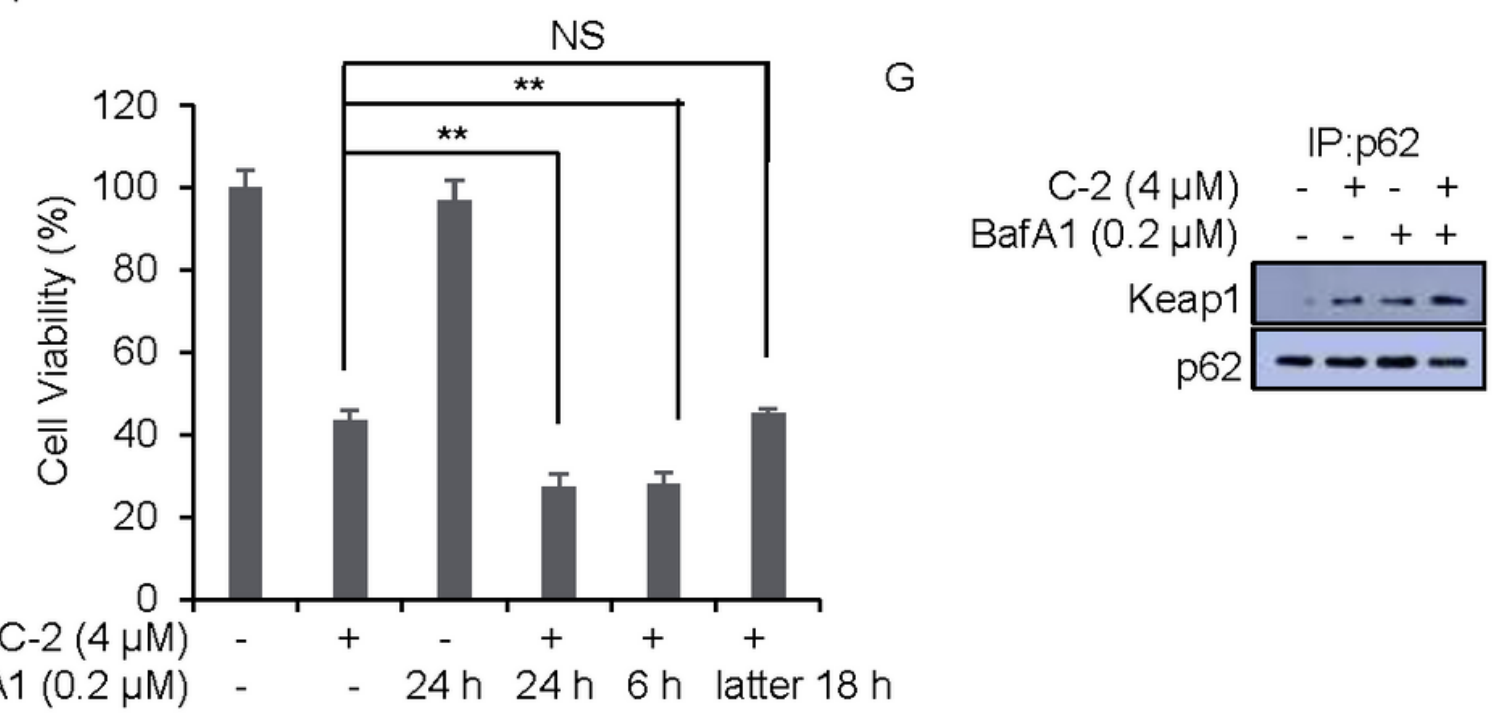

Figure 6

Inhibition of JNK/ERK antagonizes C-2 induced p62/keap1 interaction. a MGC803 cells were pretreated with LY294002 for $1 \mathrm{~h}$ before co-treatment with C-2 for $6 \mathrm{~h}$, indicated proteins were determined by western blot. b MGC803 cells were pretreated with SP600125 or SCH77298 for $1 \mathrm{~h}$ before co-treatment with C-2 for $6 \mathrm{~h}$, indicated proteins were determined by western blot. c Indicated proteins were determined by western blot in control or Beclin-1 knockdown MGC803 cells treated with C-2 for 24 h. MGC803 cells were pretreated with SP600125 (d) or SCH77298 (e) for 1 h before co-treatment with C-2 for 6 h, IP assay was performed to detect indicated proteins. 
A $\mathrm{C}-2(4 \mu \mathrm{M})-+++$

LY294002 $(10 \mu \mathrm{M}) \quad-\quad++$

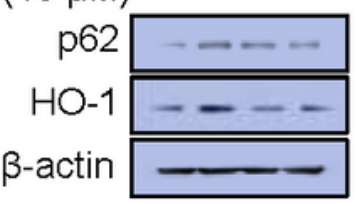

C

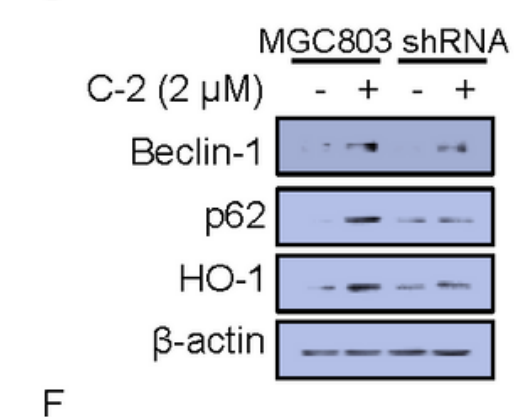

B $\mathrm{C}-2(4 \mu \mathrm{M}) \quad-++$ SP600125 $(3 \mu \mathrm{M}) \quad \ldots++$

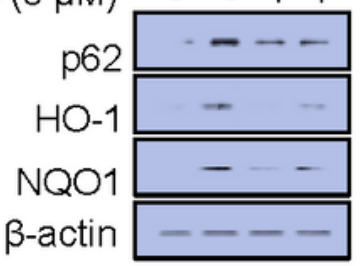

$\mathrm{D}$

IP:Keap1

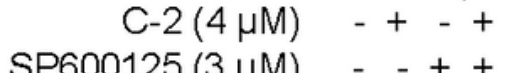

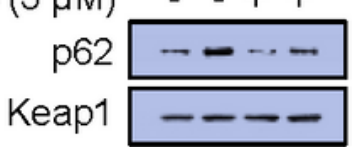

$\mathrm{C}-2(4 \mu \mathrm{M}) \quad-++$ $\mathrm{SCH} 772984(1 \mu \mathrm{M}) \quad-\quad+\quad+$

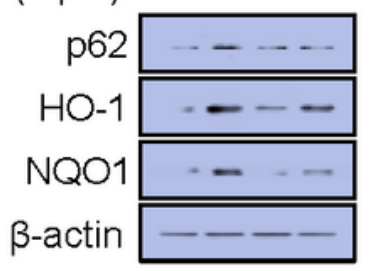

E

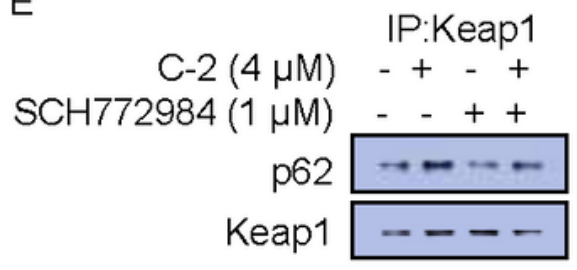

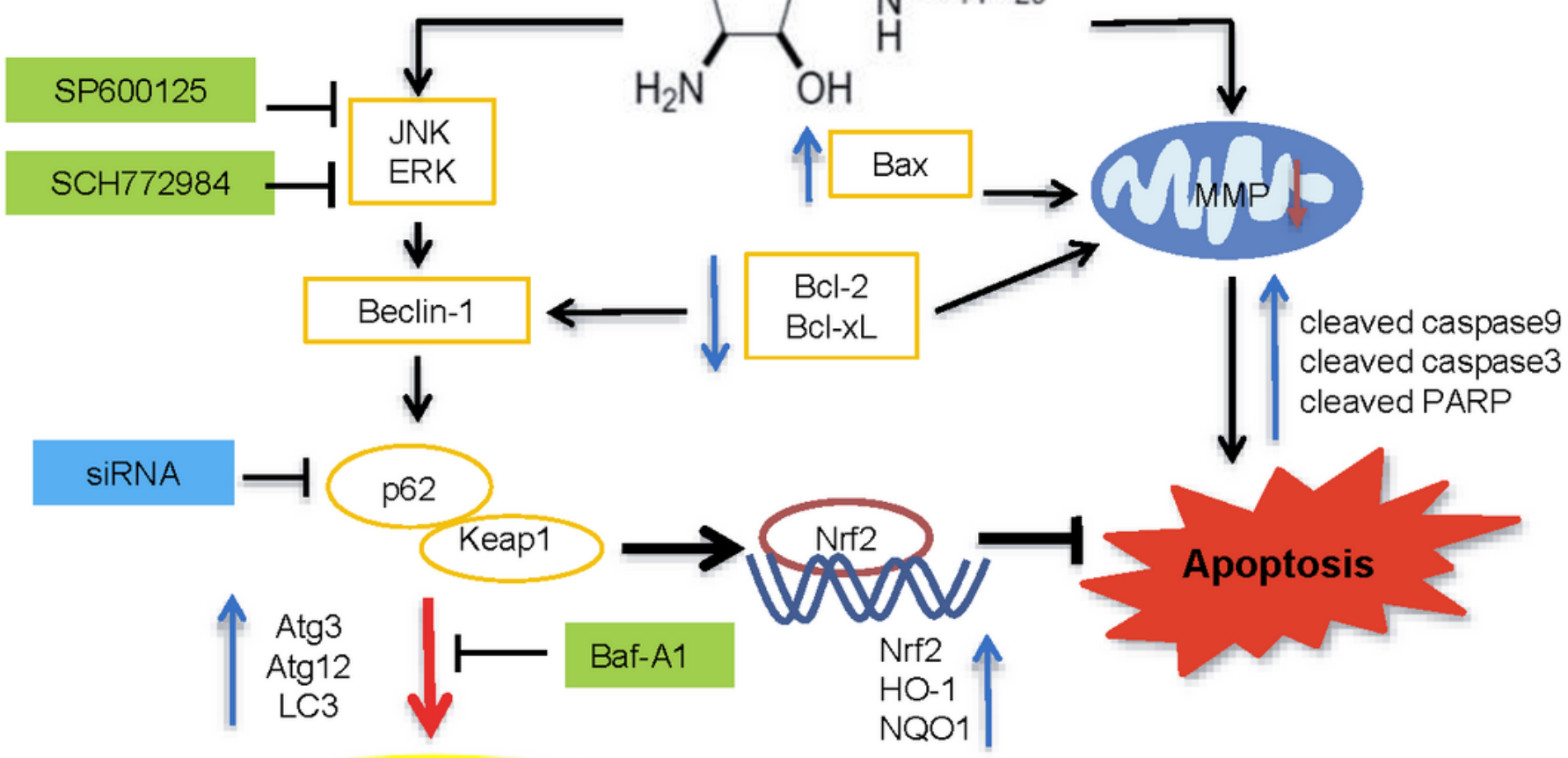

Autophagy

\section{Figure 7}

Inhibition of JNK/ERK antagonizes C-2 induced p62/keap1 interaction. a MGC803 cells were pretreated with LY294002 for $1 \mathrm{~h}$ before co-treatment with C-2 for $6 \mathrm{~h}$, indicated proteins were determined by western blot. b MGC803 cells were pretreated with SP600125 or SCH77298 for $1 \mathrm{~h}$ before co-treatment with C-2 for $6 \mathrm{~h}$, indicated proteins were determined by western blot. c Indicated proteins were determined by western blot in control or Beclin-1 knockdown MGC803 cells treated with C-2 for 24 h. MGC803 cells were 
pretreated with SP600125 (d) or SCH77298 (e) for $1 \mathrm{~h}$ before co-treatment with C-2 for 6 h, IP assay was performed to detect indicated proteins. $f$ Schematic illustration of compound $\mathrm{C} 2$ inducing cell apoptosis and autophagy. C-6 induced early autophagy antagonized cell apoptosis through Nrf2 (bold black line), and C-2 induced late autophagy had minor effect on cell apoptosis (bold red line).

\section{Supplementary Files}

This is a list of supplementary files associated with this preprint. Click to download.

- Additionalfile1.docx 